\title{
Normal Force Calibration Method Used for Calibration of Atomic Force Microscope
}

\author{
M. EKWIŃSKA ${ }^{a}$ AND Z. RYMUZA ${ }^{b}$ \\ ${ }^{a}$ Institute of Electron Technology, al. Lotników 32/46, 02-668 Warsaw, Poland \\ ${ }^{b}$ Warsaw University of Technology, Institute of Micromechanics and Photonics, A. Boboli 8, Warsaw, Poland \\ Development of new technologies for micro/nanostructures is connected with introduction of new materials \\ or with application of already existing ones in micro- and nanoscale. Unfortunately material parameters in macro- \\ and micro/nanoscale are not the same. For this reason it has become crucial to identify nanomechanical properties \\ of materials commonly used in micro- and nanostructures technology. One of the tests used for that purpose is \\ nanowear test made on the atomic force microscope. However, to obtain quantitative results of measurements, \\ precision calibration step is necessary. In this paper a novel approach to calibration of normal force, which is \\ acting on the tip of an atomic force microscope cantilever, is discussed. Presented method is based on application \\ of known normal force directly on the tip using special test structure. Such an approach allows for measurements \\ of nanowear parameters (force, displacement) with uncertainty better than $\pm 3 \%$. Authors present and discuss \\ different constructions of calibration samples. A comparison of described method with already existing ones is \\ also presented.
}

PACS numbers: 07.79.Lh, 68.37.Ps, 06.20.fb, 06.20.F-, 81.70.Bt, 06.20.-f

\section{Introduction}

The actual trend for miniaturization of mechanical components causes not only change of manufacturing technology from conventional ones to silicon technology, but most of all causes necessity to describe the behavior of micro electro mechanical system (MEMS) in the scale in which they operate. In micro- and nanoscale forces applied as well as areas of contact are much smaller than in macroscale. In addition forces such as adhesion or capillary forces have significant influence in microscale in comparison to macroscale. Under these circumstances the well known material parameters from macroscale are not applicable in microscale and the easiest way to describe material properties in microscale is to perform an experiment in the same scale. Such investigations can be done with the use of atomic force microscope (AFM), which is a powerful tool for estimation of e.g. wear resistance of materials in micro- and nanoscale [1]. AFM is composed of probe scanner, probes displacement detector, electronics connected with computer and system of isolation from vibrations. Piezoelectric scanner enables to achieve movement between the sample and the probe. The probe is a cantilever with sharp (cone or pyramidal) tip at one end. The detecting system of cantilever's displacement is usually a laser beam and a four-segment photodiode. The laser beam falls on one end of cantilever, reflects there and falls on the detector where the change of the laser beam position is converted on the force (lateral or normal) signal in arbitrary units [a.u.].

\section{Calibration method}

That causes the need for calibration of these forces. In the literature several calibration techniques as far as normal forces are concerned. Most of them are two stage ones [2-10]. In the first step normal stiffness of cantilever is evaluated and this value is multiplied by the displacement. As a result real force acting on the cantilever's tip is estimated. In some of existing methods precise geometrical parameters of cantilever are needed $[6,3]$, in other methods additional expensive equipment is used (nanoindenter TriboScope [8] or thermal spectrum analyzer [9]), sometimes additional elements like calibrated tungsten balls [10] or cantilevers with already calibrated stiffness [7] are used (Table).

The biggest problem with existing normal force calibration methods is the fact that force is established as a product of stiffness and displacement. Changes of measuring signal and stage stiffness are very rarely taken into account. Under these circumstances a new approach was needed for calibration of normal force - a straightforward calibration.

The present work deals with a new calibration method of normal force calibration. In this method whole AFM is treated as a black box. Extortion is a well known value of normal force applied at the end of cantilever's tip, which causes cantilever deflection, then change of position of laser beam spot on the detector, and change of the signal from the detector and finally change of the output parameter: change of normal force signal in arbitrary units. Comparison of applied force in $[\mathrm{nN}]$ and received from the device force in [a.u.] enables estimation of calibration parameter $K[\mathrm{nN} / \mathrm{a} . \mathrm{u}]$. 
TABLE

Summary of different techniques for cantilever stiffness measurement.

\begin{tabular}{|c|c|c|}
\hline Method & $\begin{array}{l}\text { Uncertainty in } \% \text { of measured } \\
\text { stiffness value }\end{array}$ & Disadvantages \\
\hline analytical $[6,3]$ & maximum $100 \%$ & $\begin{array}{l}\text { precise measurement of nanometer } \\
\text { range dimensions [12] }\end{array}$ \\
\hline $\begin{array}{l}\text { finite element method } \\
(\mathrm{FEM})\end{array}$ & $\begin{array}{l}\text { achieved results should not be } \\
\text { considered as quantitative ones }\end{array}$ & $\begin{array}{l}\text { mechanical material parameters } \\
\text { in microscale needed }\end{array}$ \\
\hline $\begin{array}{l}\text { destructive deflection } \\
\text { by nanoindenter [8] }\end{array}$ & $\begin{array}{l}10 \% \text {, depending on measured stiffness } \\
\text { and cantilever mounting system }\end{array}$ & $\begin{array}{l}\text { impossibility of further use } \\
\text { of cantilever }\end{array}$ \\
\hline $\begin{array}{l}\text { non-destructive deflection } \\
\text { by nanoindenter [8] }\end{array}$ & $\begin{array}{l}10 \% \text {, depending on measured stiffness } \\
\text { and cantilever mounting system }\end{array}$ & stiffness of fixation not included \\
\hline Cleveland method [10] & $10 \%$ & $\begin{array}{l}\text { potentially destructive, cantilever } \\
\text { movement calibration required }\end{array}$ \\
\hline Sader [4] method & $20 \%$ & $\begin{array}{l}\text { application of particular environmental } \\
\text { conditions, isolation form air vibrations } \\
\text { or temperature fluctuations }\end{array}$ \\
\hline Hutter [5] method & $20 \%$ & $\begin{array}{l}\text { application of particular environmental } \\
\text { conditions, isolation form air vibrations } \\
\text { or temperature fluctuations }\end{array}$ \\
\hline Gibson method [7] & $\begin{array}{l}10-30 \% \text { depending on ratio of stiffness } \\
\text { of two probes used }\end{array}$ & $\begin{array}{l}\text { best for two probes of similar stiffness, } \\
\text { require accurate probe positioning, } \\
\text { potentially destructive }\end{array}$ \\
\hline
\end{tabular}

\section{Calibration sample}

In order to calibrate normal force, a sample with elastic element was designed and manufactured (Fig. 1). There are three main parts of the elastic sample: surface where cantilever's tip is located (1) with specially prepared roughness, membrane (2), surface to which AFM table is mounted (3). During calibration of the normal force in AFM with this calibration device it is placed on the AFM table and cantilever's tip is approached to the surface (1). After obtaining contact tip is retracted several nanometers above sample surface. Then a force distance curve measurement is made. During that measurement cantilever's tip is approached to the sample surface. When the contact is reached the tip is pushed until elastic deflection is obtained. During the first step of the calibration procedure a stiff bulk sample is used to define deflection of the cantilever on the applied displacement. When the deflection of the cantilever is known, the stiff bulk sample is replaced with a calibration sample with the elastic element. During force distance curve measurement the cantilever and elastic calibration sample deflect under applied displacement. Small deflection which is applied on the membrane (2) is estimated using information about whole achieved displacement and cantilever deflection which was gained earlier. The small displacement of the membrane (2) multiplied by the stiffness of the calibrating sample (which has to be done earlier) is the real value of applied force which is acting on the can-

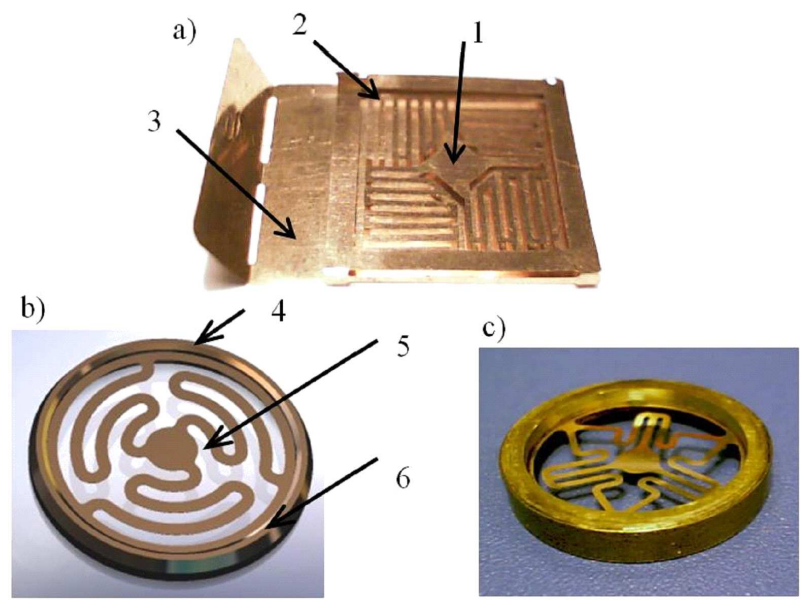

Fig. 1. Various construction of calibration samples; 1 - area where AFM's tip stands during the calibration, 2 - membrane, which is elastically deformed during calibration, 3 - holder of device, 4 - calibration sample holder, 5 - area where AFM's tip stands during calibration, 6 - membrane, which is elastically deformed during calibration.

tilever's tip. This force causes deflection of the cantilever and the change of the normal force signal in arbitrary units. As a result of the calibration of the AFM force distance curved is achieved.

Due to monolithic structure of the calibration sample and usage of the AFM scanner as an element respon- 


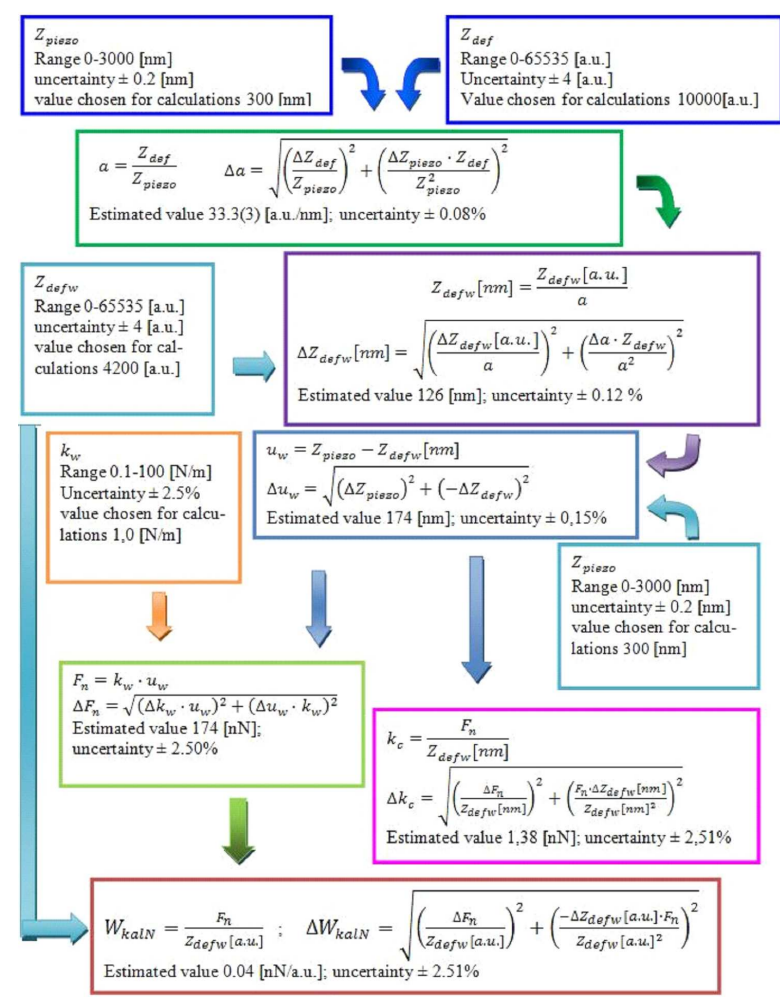

Fig. 2. Estimation of the uncertainty of the normal force calibration method; $F_{\mathrm{N}}$ - normal force that act on the cantilever tip during calibration, $k_{w}$ - stiffness of calibration sample, $u_{w}$ - deflection of calibration sample, $Z_{\operatorname{def} w}$ [a.u.] - cantilever deflection during measurement on the calibration sample; $Z_{\text {def }}$ - cantilever deflection during measurement on the stiff bulk sample; $Z_{\text {piezo }}$ - total displacement of AFM table which is applied during calibration; $a-$ slope of $Z_{\text {def }}=f\left(Z_{\text {piezo }}\right)$ curve, during measurement on stiff bulk sample; $Z_{\text {def } w}$ $[\mathrm{nm}]$ - cantilever deflection during calibration with calibration sample; $k_{c}$ - cantilever stiffness.

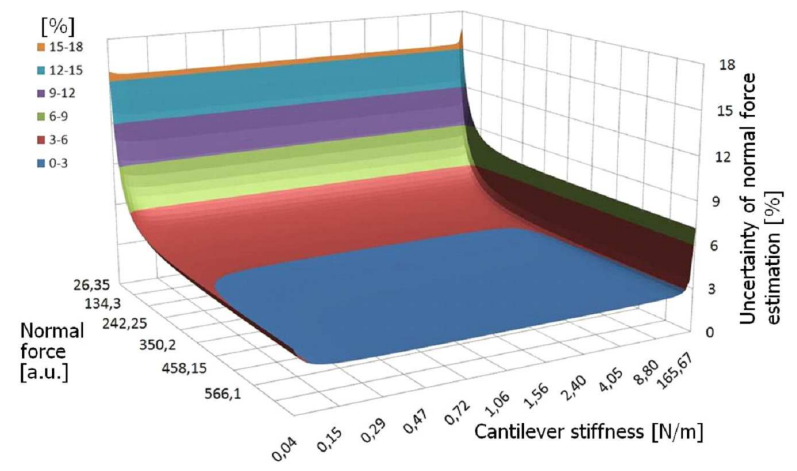

Fig. 3. Uncertainty of the real value of normal force estimation according to value of measured normal force and cantilever stiffness, calibration sample stiffness $k_{w}=1 \mathrm{~N} / \mathrm{m}$, uncertainty of the stiffness of the calibration sample $\pm 0.025 \mathrm{~N} / \mathrm{m}$ (2.5\% of stiffness value). sible for calibration sample movements the calibration procedure is simple and can be done straight on cantilever mounted on AFM just before or just after wear test measurements. Uncertainty of the presented calibration method does not exceed $\pm 3 \%$. Figure 2 presents schematic estimation of the uncertainty of the calibration method.

Apart from uncertainty of the AFM measurements and uncertainty of the calibration of normal force the range of force has big influence on the measurement results. Results of estimation of uncertainty for different force ranges is presented in Fig. 3. It can be seen that inaccuracies do not exceed $40 \%$ for the worst case. The worst case is when calibrating procedure is made for very small piezoscaner movements ranges (e.g. several dozen of nanometers), and when measurements after calibration are within several dozen [a.u.].

\section{Conclusions}

A new method of calibration of normal force in AFM was presented. In this approach cantilever is fixed on the AFM in the same way as during measurements and a new calibration device is being used for estimation of relationship between normal force in arbitrary units and applied force is nanonewtons. Presented calibration method is novel, easy to use on and specified for cantilever that is already mounted in the AFM system. The primary source of the calibration uncertainty as well as uncertainty during later normal force measurements is the uncertainty of calibration of the calibration sample.

Using presented method uncertainty of calibration of normal force in AFM does not exceed $\pm 3 \%$. To do this such conditions should be fulfilled:

- uncertainty of the stiffness of normal force calibration sample should not exceed $\pm 2.5 \%$;

- stiffness of the measuring cantilever should not depart far from the stiffness of the calibrating sample (it should not be smaller than $0.7 k_{w}$ and in the same time it should not be higher than $10 k_{w}$, where $k_{w}=$ stiffness of calibrating sample);

- forces ranges during calibration and after it should not be smaller than $0.5 \%$ of measuring range of the AFM;

- applied displacements ranges during calibration and after it should not be smaller than $0.5 \%$ of measuring range of the AFM.

This method enables to obtain better precision of measurements than with the use of methods known from the literature. Besides it can be used for all types of cantilevers and does not depend on clamping of the cantilever or stiffness of the whole measuring unit. 


\section{References}

[1] G. Binnig, C.F. Quate, Ch. Gerber, Phys. Rev. Lett. 56, 930 (1986).

[2] B. Bhushan, Handbook of Micro/Nano Tribology, 2nd ed., CRC Press, Boca Raton 1998.

[3] J.M. Neumeister, W.A. Ducker, Rev. Sci. Instrum. 65, 2527 (2008).

[4] J.E. Sader, I. Larson, P. Mulvaney, L.R. White, Rev. Sci. Instrum. 66, 3789 (1995).

[5] J.L. Hutter, J. Bechhoefer, Rev. Sci. Lett. 64, 1868 (1993).

[6] N.A. Burnham, X. C, C.S. Hodges, G.A. Matei, E.J. Thoreson, C.J. Roberts, M.C. Davies, S.J. Tenler, Nanotechnology 14, 1 (2003).
[7] Ch.T. Gibson, G.S. Watson, S. Myhra, Nanotechno$\log y$ 7, 259 (1996).

[8] J.D. Holbery, V.L. Eden, J. Micromech. Microeng. 10, 85 (2000).

[9] R. Levy, M. Maaloum, Nanotechnology 13, 33 (2002).

[10] J.P. Cleveland, S. Manne, D. Bocek, P.K. Hansma, Rev. Sci. Instrum. 64, 403 (1993).

[11] M. Ekwińska, G. Ekwiński, Z. Rymuza, Eds. R. Jabłoński, M. Turkowski, R. Szewczyk, Springer-Verlag, Berlin 2007, p. 505.

[12] Ultrasharp Cantilevers and Gratings, catalogue of products made by MikroMasch, 2003. 